\title{
Synthesis of N-2-Hydroxyethyltrichloroacetamide Possible Precursor to Polycarbamate
}

Chang Cui and Jun H. Shin*

Department of Chemistry, Queensborough Community College, Bayside, NY 11364

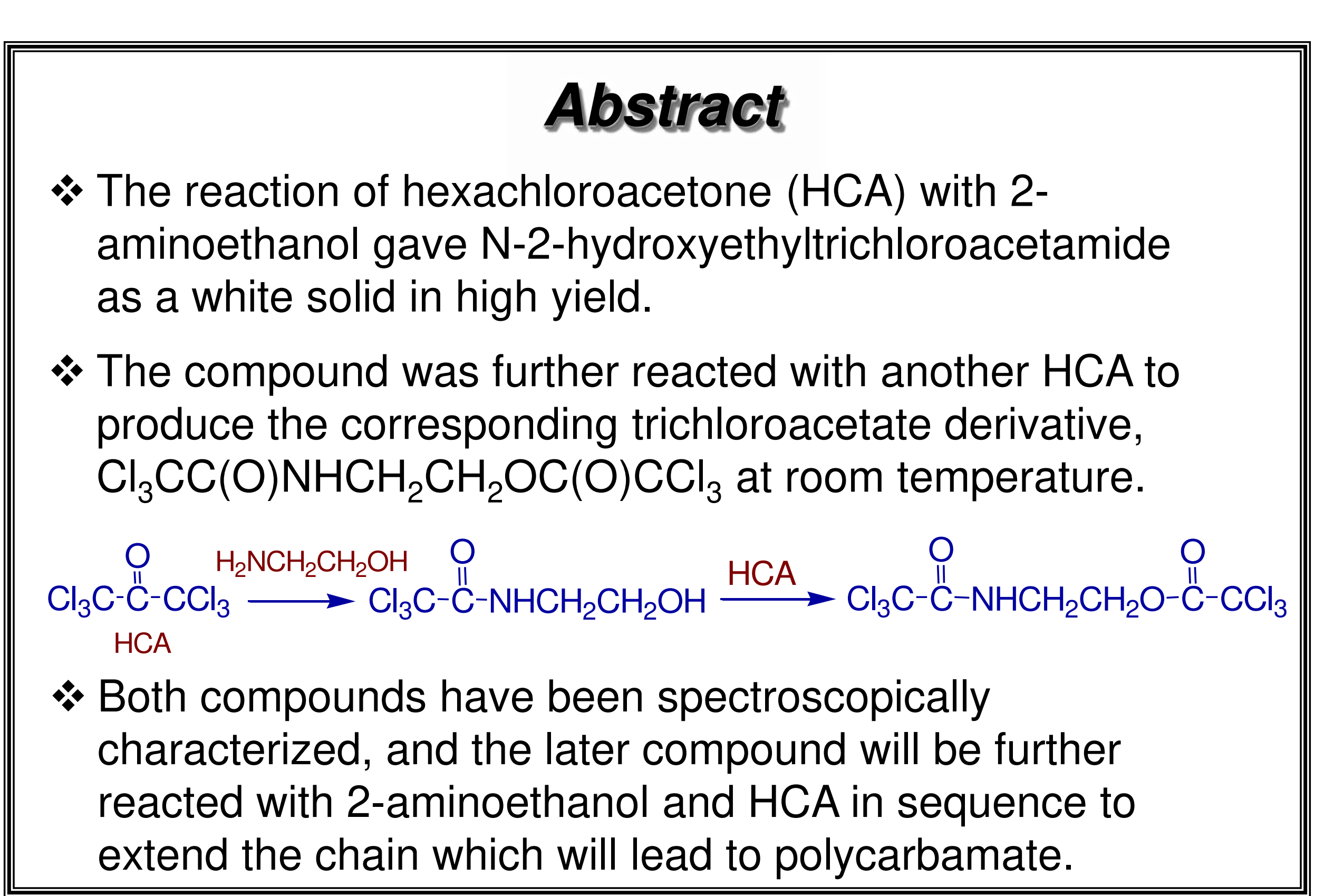

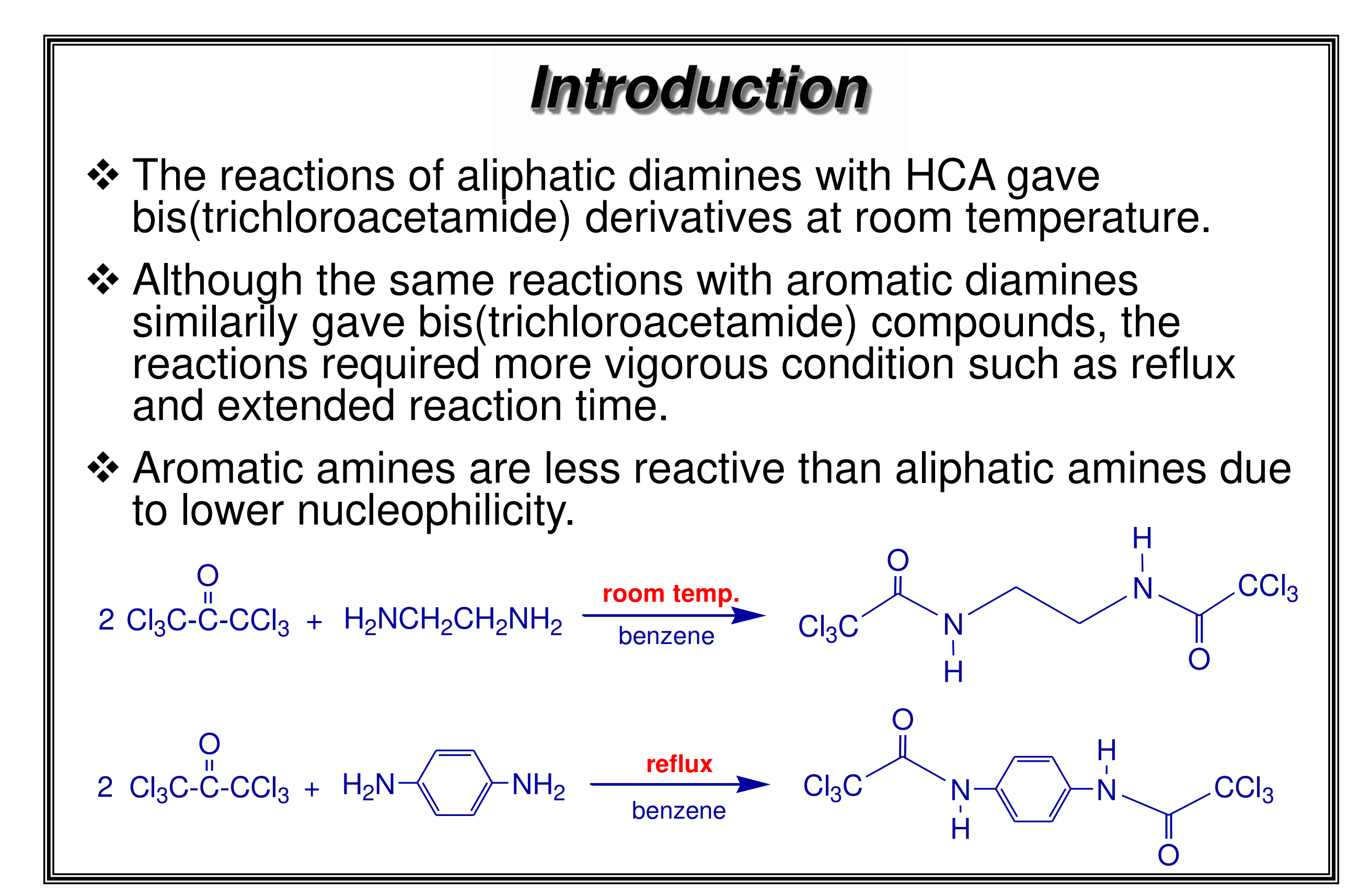

\section{Introduction}

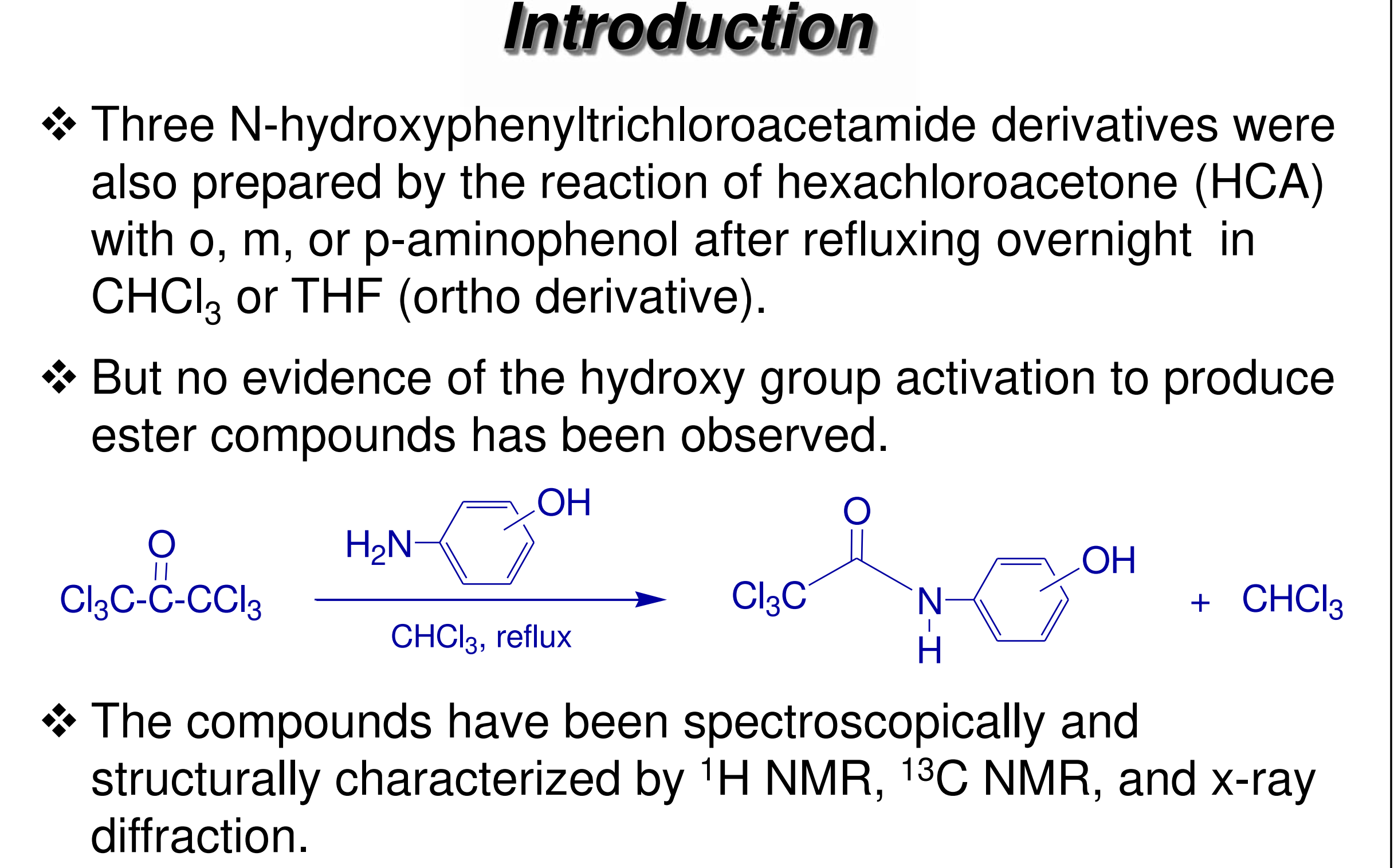
Structurally
diffraction.

Preparation of Aromatic Polycarbamates
* Various reactions have been carried out with the three $\mathrm{N}$ -
hydroxyphenyltrichloroacetamide derivatives to produce
polycarbamates through a reflux process in DMSO or
DMF, and by using a microwave reactor, however, no
reaction has successfully produced polycarbamate yet.
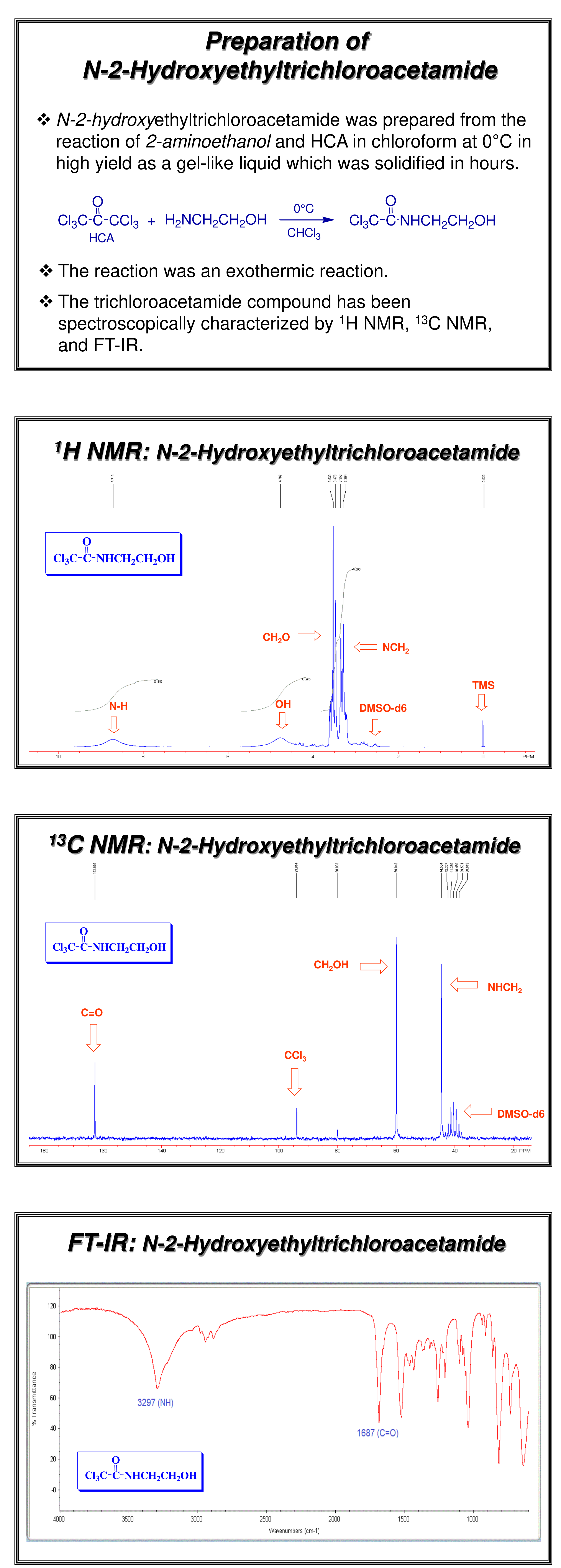
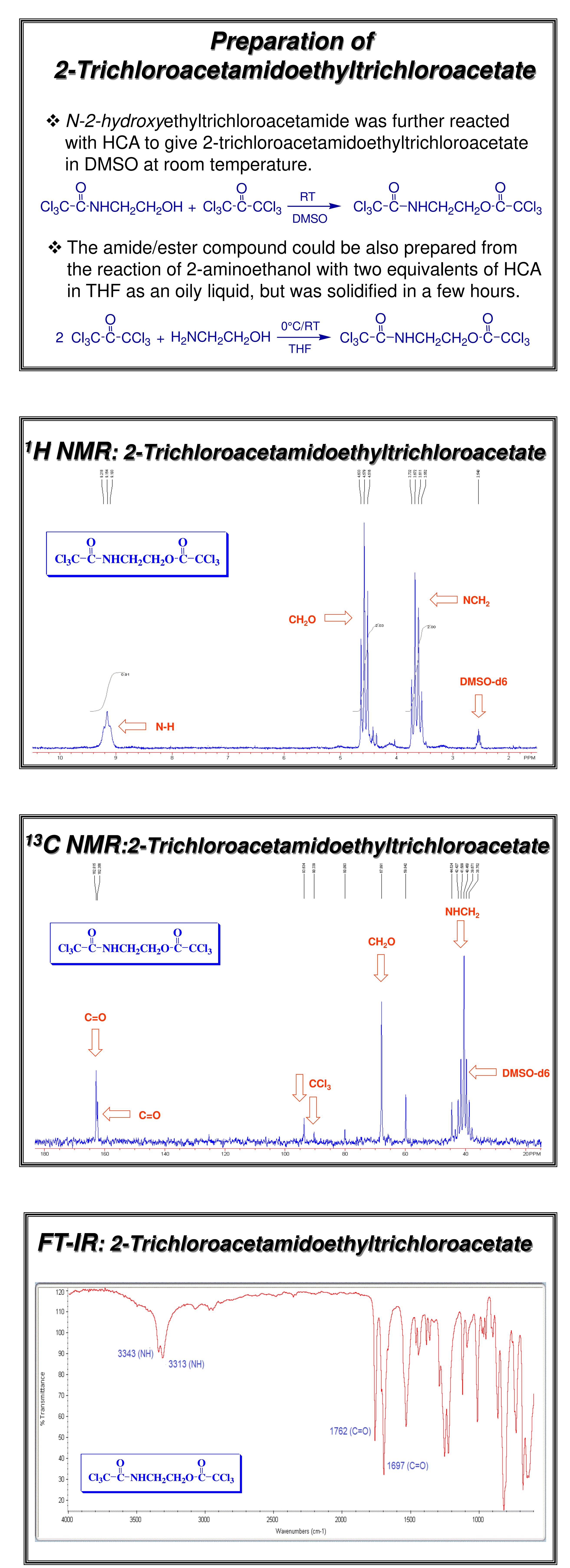
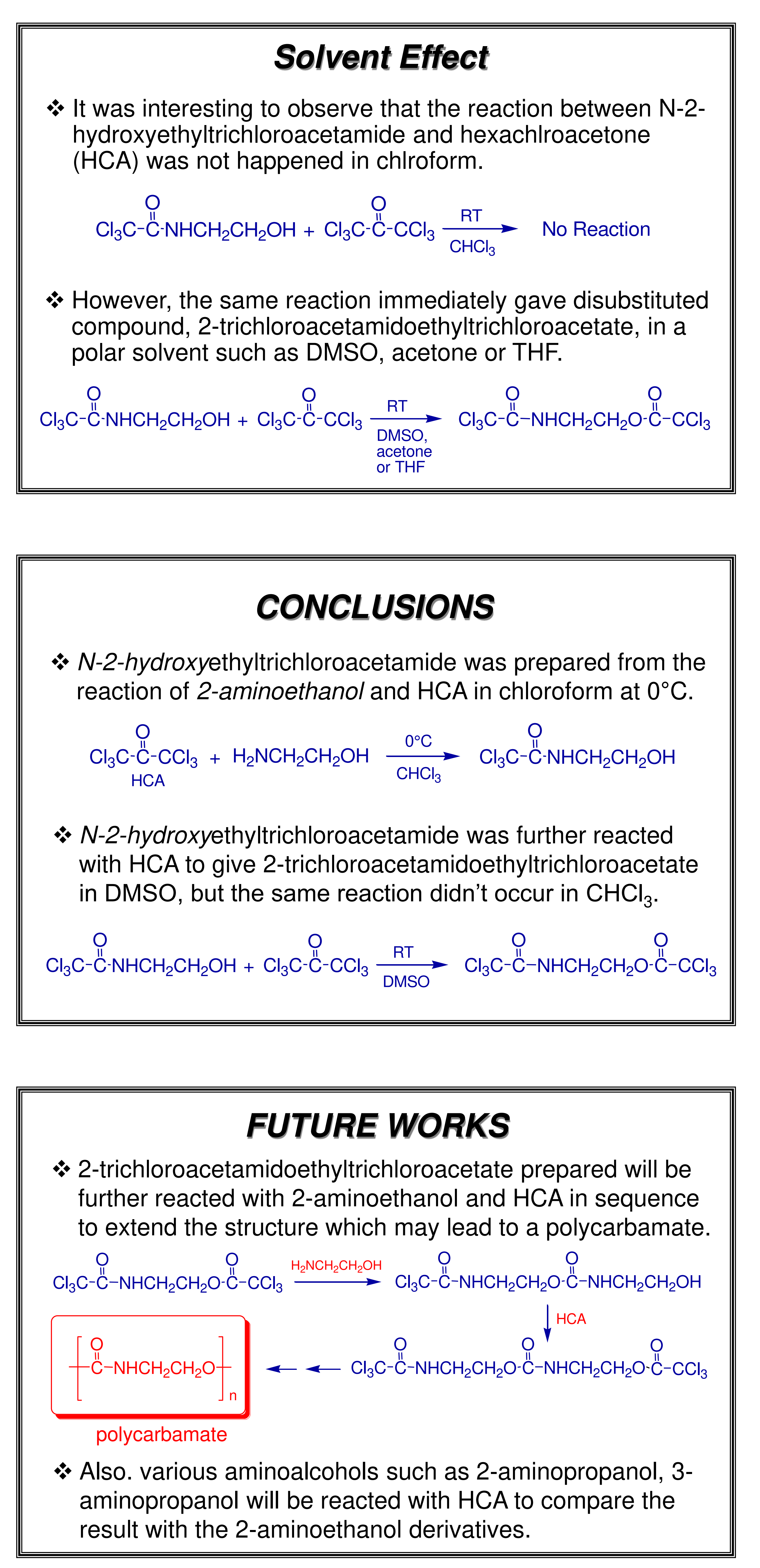

\section{ACKNOWLEDGEMENT}

Dr. Jun H. Shin

Dr. David Sarno

Samuel Yi

Department of Chemistry of QCC The CUNY Research Scholars Program PSC-CUNY Research Award 